\title{
Root-Fusion Characteristic of Eucalyptus Trees Block Gully Development
}

\author{
Dalmas O. Sigunga $^{{ }^{*}}$, Makoto Kimura ${ }^{2}$, Mitsuo Hoshino ${ }^{2}$, Shuichi Asanuma ${ }^{2}$, John C. Onyango ${ }^{1}$ \\ ${ }^{1}$ Maseno University, Maseno, Kenya; ${ }^{2}$ Graduate School of Bioagricultural Science, Nagoya University, Nagoya, Japan. \\ Email: *dalsigunga@yahoo.com
}

Received June $26^{\text {th }}$, 2013; revised July 28 ${ }^{\text {th }}, 2013$; accepted August $19^{\text {th }}, 2013$

Copyright (C 2013 Dalmas O. Sigunga et al. This is an open access article distributed under the Creative Commons Attribution License, which permits unrestricted use, distribution, and reproduction in any medium, provided the original work is properly cited.

\begin{abstract}
Soil erosion by water resulting in gully formation is a common occurrence in western Kenya. Establishment of local and sustainable countermeasures to prevent gully development/expansion in western Kenya is an urgent issue. This study presents the proposal to prevent gully development/expansion by planting Eucalyptus trees in gully prone regions. A survey study was undertaken in Kenya from 2008 to 2011. Roots of adjacent Eucalyptus citriodora trees fused forming a dense network of closely woven mass of root system holding large amount of soil thereby checking erosion by water and hence gully development. The network of roots among adjacent Eucalyptus trees also supported the standing and normal growth of the other Eucalyptus trees whose root systems were completely free from soil. Recognizable aging and breakdown of root networks were not observed during the survey period.
\end{abstract}

Keywords: Eucalyptus citriodora; Gully Erosion; Root-Fusion; Root System

\section{Introduction}

Food production in Kenya has declined over the past several years [1]. One of the main causes of the decline was the mismanagement of land/soil resources [2]. Soil erosion by water was the most extensive and serious land degradation problem undermining crop production with the resultant increase in food insecurity in Kenya [3]. Recommended soil erosion control measures in the country [4,5] are so far ineffective against gully erosion.

Gully erosion in the area is classified into two erosion pattern types: Awach-type and Sondu-type. A deep single channel, perpendicular banks, and distinct head-cuts presumably formed by stream flows and mass wasting characterize Awach-type gullies. In contrast, braised shallow channel beds characterize Sondu-type gullies [69]. Sigunga et al. studied physical and chemical properties of soil that promote soil erosion of Awach-type and characterized it with alkaline $\mathrm{pH}$, high exchangeable sodium percentage, fragile soil structure, high dispersibility, and low infiltration rate [10]. Due to their physical and chemical properties and steep geomorphic conditions, slumping of bank walls occurred in places along the gully.

It was noticed, at one of the Awach-type erosion sites,

*Corresponding author. that some roots of adjacent Eucalyptus citriodora trees fused forming a dense network of closely woven mass of root system holding large amount of soil even after the soil layers below the root system had been washed away. The enormous capacity of E. citriodora roots to fuse and form a dense connection of roots between adjacent Eucalyptus trees can provide a local sustainable countermeasure to prevent the development/expansion of gully fronts. Eucalyptus tree was introduced into Kenya from Australia in the early 1902, and since then it was grown in almost all the agro-ecological zones (AEZs) across the country [11]. About 100 species of Eucalyptus have been introduced into the country but only 9 species and 2 hybrids are recommended for various AEZs covering the whole country [12]. Eucalyptus trees grow fast and provide economic products including poles for power line transmission, building, fencing, plywood, pulp, fuel wood, perfume and tannin. They also provide windbreaks and carbon sequestration. Eucalyptus trees are characterized by high coppice ability (profuse and rapid stem re-growth from cut stems).

Eucalyptus trees are common in western and central Kenya and are grown along the boundary of estates and farmlands. Four species of Eucalyptus are recommended for western Kenya (E. citriodora, E. grandis, E. camaldulensis and E. saligna) [12]. Growing of Eucalyptus 
trees is, thus, a technology already with farmers in western Kenya. The farmers within areas prone to gully erosion should be encouraged to grow Eucalyptus trees to prevent gully formation and/or expansion and also for direct economic gains from the sales of various Eucalyptus products. This study presents the evidence that Eucalyptus trees can be used, given the root-fusion characteristic of adjacent trees, to prevent gully formation and/or expansion. The evidence presented here is based on a field survey in Kenya.

\section{Methodology}

Field survey was conducted at Kokal village (S0¹6'35.3", E34 ${ }^{\circ}$ 58'46.6") in Kisumu, western Kenya, in August 2008, March and May 2009 and August 2011 and at Luanda village in Kisumu in March 2011. Field survey was also conducted at Kenya Israel village near Machakos town (S1 $\left.{ }^{\circ} 31^{\prime} 10.4^{\prime \prime}, \mathrm{E}^{\circ}{ }^{\circ} 14{ }^{\prime} 48.3^{\prime \prime}\right)$, eastern Kenya, in August 2011. The evidence of Eucalyptus trees blocking gully erosion was photographed.

\section{Results and Discussion}

Gully erosion to the depth of $1-3 \mathrm{~m}$ is common in Kisumu area and the depth is within the root systems of Eucalyptus trees. At the Awach-type erosion site in Kokal village the gully expanded during the 3-year period [10]. In the absence of Eucalyptus trees the gully expanded by slumping of banks (Figures 1(a) and (b)). In contrast, the site where Eucalyptus trees (E. citriodora) grew along the bank of the stream did not result in gully expansion during the 3-year period. The root system of Eucalyptus trees held large soil mass, prevented the slumping of bank wall by water erosion, and blocked further development of the gully (Figures 1(c)-(e)).

The blocking of gully erosion was not by the root system of an individual Eucalyptus tree but by the root sys-
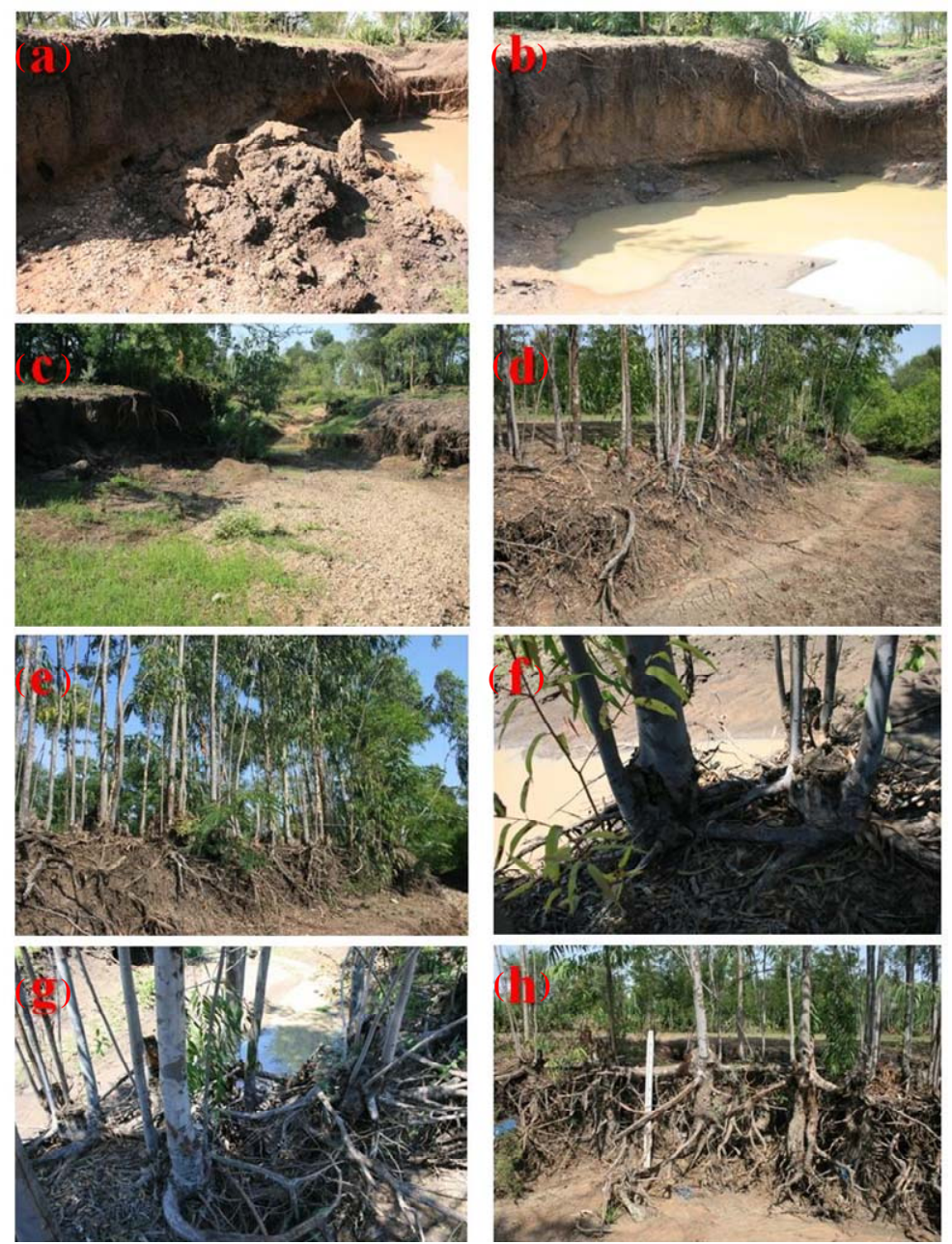

Figure 1. Field survey of Eucalyptus root system and its performance in blocking gully erosion development at Kokal village in Kisumu, western Kenya. Slumping of gully walls occur in the absence of Eucalyptus roots (a)-(c). Eucalyptus root system hold large soil mass preventing slumping of gully walls (c)-(e). Eucalyptus roots fused forming intimate mass of root system (f), (g). Neighboring Eucalyptus supported adjacent tree whose roots were freed of soil by water erosion (h). 
tem networks between adjacent Eucalyptus trees. Their roots were connected intimately to each other by root fusions (Figures 1(f) and (g)). The network of roots among adjacent Eucalyptus trees by root fusion also supported the standing of the tree whose root system was completely free from soil. Besides, fused-root system seemed to supply the nutrients and water from the neighbors to the Eucalyptus tree whose root system was completely free from soil by soil erosion and which kept green as neighbors (Figure 1(h)). Recognizable aging and breakdown of root networks between adjacent trees were not observed during the survey period.

The root fusion was common occurrence for Eucalyptus trees and it was observed at Luanda village in Kisumu (Figures 2(a)-(c)). Any soil erosion was not observed at the site where the trees were grown along the border of upland fields (Figures 2(d)-(f)). Root fusion of Eucalyptus trees was also found at Kenya Israel village near Machakos town, eastern Kenya (Figures 2(g) and (h)). Gully erosion at the site reached to 3-m depth and dense root network of Eucalyptus trees completely blocked further gully expansion. Eucalyptus trees were nearly $20 \mathrm{~m}$ tall (Figure 2(e)) and root systems and root networks were denser than those observed in Kisumu (Figures 2(f) and (g)). Some roots were platy in appearance and held the soil completely inside the platy mass of roots (Figure $2(\mathbf{h})$ ).

On the way from Nairobi to Machakos, gully erosion was developed in large areas, which was partly due to natural soil erosion by water and partly to sand mining for construction. The areas with gully erosion, where Eucalyptus trees were planted had gully expansion
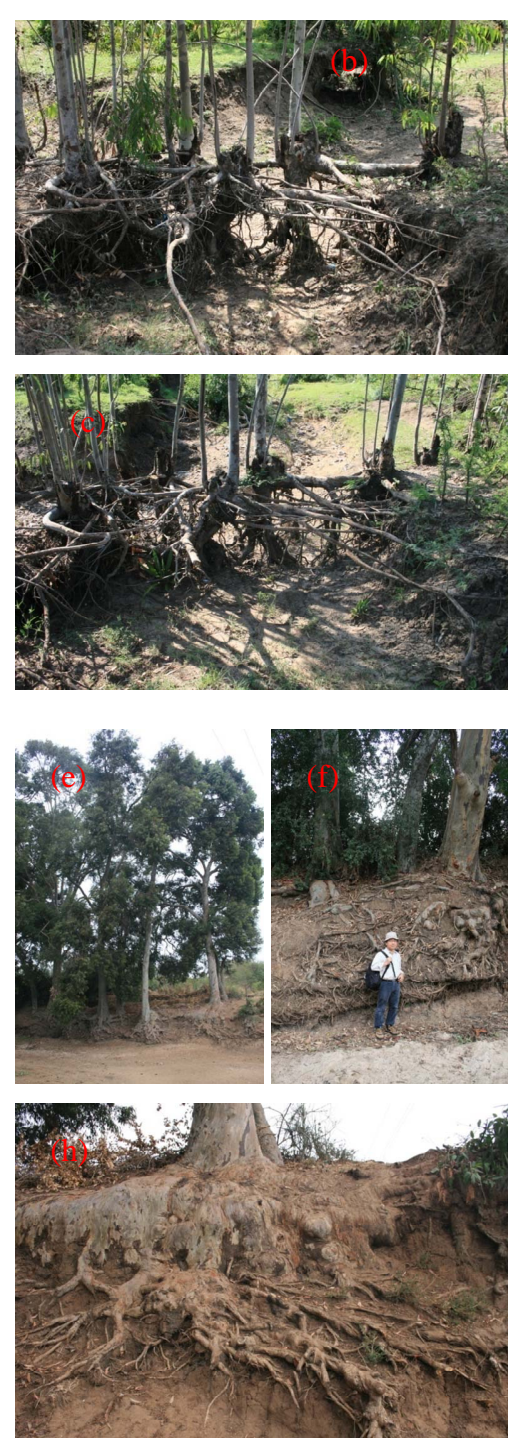

Figure 2. Field survey of Eucalyptus root fusion in Kenya. Eucalyptus root fusion phenomenon was also observed at Luanda village in Kisumu, western Kenya (a, b, c) and at Kenya Israel village in Machakos, eastern Kenya (d, e, f, g, h). Eucalyptus root fusion takes different forms $(\mathrm{g}, \mathrm{h})$. 
checked. There were areas with gullies along the same route with no Eucalyptus trees planted. Thus, the growing of Eucalyptus trees was haphazard and was not meant to control gully development. In this study, root fusion phenomenon in other tree species than E. citriodora was not elucidated.

Robust root fusion trait of Eucalyptus (E. citriodora) and performance of its root system in holding large mass of soils against water erosion make Eucalyptus trees a recommendable countermeasure to check the development and/or expansion of gully due to water erosion in western Kenya.

\section{Acknowledgements}

The authors are grateful to Japan Society for the Promotion of Science for financial support (Grand-in-Aid No. 20255009).

\section{REFERENCES}

[1] Central Bureau of Statistics, "Kenya Facts and Figures," Ministry of Planning and National Development, Nairobi, 2006.

[2] P. A. Sanchez, K. D. Shepherd, M. Soule, F. M. Place, R. J. Buresh, A. N. Izac, A. U. Mokwunye, F. R. Kwesiga, C. G. Nderitu and P. Woomer, "Soil Fertility Replenishment in Africa: An Investment in Natural Resource Capital,” In: R. J. Buresh et al., Eds., Replenishing Soil Fertility in Africa, SSSA Special Publication No. 5, Soil Science Society of America, Madison, 1997, pp. 1-46.

[3] FAO, 2010. http://faostat.fao.org/site/567/default.aspx

[4] C. G. Wenner, "Soil Conservation: Pocket Book for Tech- nical Assistants,” Ministry of Agriculture, Nairobi, 1980, 33 pages.

[5] C. G. Wenner, "Soil Conservation in Kenya,” Ministry of Agriculture, Nairobi, 1981, 49 pages.

[6] M. Hoshino, Y. Katsurada, K. Yamamoto, H. Yoshida, M. Kadohira, K. Sugitani, J. M. Nyangaga, J. I. Kinyamario and E. K. Kangéthe, "Gully Erosion in Western Kenya,” The Geological Society of Japan, Vol. 110, No. 2, 2004, pp. 3-4.

[7] M. Hoshino, "Soil Erosion and Conservation in Western Kenya," Report of the Research Project No. (A) 152530 06 (2003-2005), the Grant-in-Aid for Scientific Research (Overseas Scientific Survey) from Japan Society for the Promotion of Science, 2006, p. 96.

[8] Y. Katsurada, "Regional Scaled Mapping of Gully Erosion Sensitivity in Western Kenya," African Journal of Environmental Science and Technology, Vol. 1, No. 3, 2007, pp. 49-52.

[9] Y. Katsurada, M. Hoshino, K. Yamamoto, H. Yoshida and K. Sugitani, “Gully Retreat of Awach-Kano Gullies, Nyanza Province, Kenya: Field Measurements and PixelBased Upslope Catchment Assessment,” African Study Monographs, Vol. 28, No. 3, 2007, pp. 125-141.

[10] D. O. Sigunga, M. Hoshino, J. C. Onyango, S. Asanuma and M. Kimura, "Pedological Perspective of Gully Erosion Sites within Kendu Escarpment-Sondu Miriu Region, West Kenya," African Journal of Environmental Science and Technology, Vol. 5, 2011, pp. 1050-1059.

[11] Anon. "A Guide to On-Farm Eucalyptus Growing in Kenya,” Kenya Forest Services, Nairobi, 2009, 36 pages.

[12] P. O. Oballa, P. K. A. Konuche, M. N. Muchiri and B. N. Kigomo, "Facts on Growing and Use of Eucalyptus in Kenya,” Kenya Forestry Research Institute, Nairobi, 2010, 30 pages. 